\title{
Patterns of pain-free response in 497 cases of classic trigeminal neuralgia treated with Gamma Knife surgery and followed up for least 1 year
}

\author{
Clinical article
}

\author{
Constantin Tuleasca, M.D., ${ }^{1,4,5}$ Romain Carron, M.D., ${ }^{1}$ \\ Noémie Resseguier, M.D., M.Sc., ${ }^{2}$ Anne Donnet, M.D., ${ }^{3}$ Philippe Roussel, M.D., ${ }^{1}$ \\ Jean Gaudart, M.D., Ph.D., ${ }^{2}$ Marc Levivier, M.D., Ph.D., ${ }^{4,5}$ and Jean RéGis, M.D. ${ }^{1}$
}

${ }^{1}$ Functional and Stereotactic Neurosurgery Unit, Centre Hospitalier Universitaire La Timone, Assistance Publique-Hopitaux de Marseille, Aix-Marseille University, INSERM, UMR 1106, Marseille; ${ }^{2}$ Department of Public Health and Medical Information, Centre Hospitalier Universitaire La Timone, Assistance Publique-Hopitaux de Marseille; Aix-Marseille University, UMR 912, SESSTIM; INSERM, UMR 912, SESSTIM; IRD, UMR 912, SESSTIM; Marseille; ${ }^{3}$ Department of Neurology, Clinical Neuroscience Federation, Centre Hospitalier Universitaire La Timone, Assistance Publique-Hopitaux de Marseille, France; ${ }^{4}$ Centre Hospitalier Universitaire Vaudois, Neurosurgery Service and Gamma Knife Center, Lausanne; and ${ }^{5}$ University of Lausanne, Faculty of Biology and Medicine, Lausanne, Switzerland

Object. The goal of this study was to establish whether clear patterns of initial pain freedom could be identified when treating patients with classic trigeminal neuralgia (TN) by using Gamma Knife surgery (GKS). The authors compared hypesthesia and pain recurrence rates to see if statistically significant differences could be found.

Methods. Between July 1992 and November 2010, 737 patients presenting with TN underwent GKS and prospective evaluation at Timone University Hospital in Marseille, France. In this study the authors analyzed the cases of 497 of these patients, who participated in follow-up longer than 1 year, did not have megadolichobasilar artery- or multiple sclerosis-related TN, and underwent GKS only once; in other words, the focus was on cases of classic TN with a single radiosurgical treatment. Radiosurgery was performed with a Leksell Gamma Knife (model B, C, or Perfexion) using both MR and CT imaging targeting. A single 4-mm isocenter was positioned in the cisternal portion of the trigeminal nerve at a median distance of $7.8 \mathrm{~mm}$ (range $4.5-14 \mathrm{~mm}$ ) anterior to the emergence of the nerve. A median maximum dose of 85 Gy (range 70-90 Gy) was delivered. Using empirical methods and assisted by a chart with clear cut-off periods of pain free distribution, the authors were able to divide patients who experienced freedom from pain into 3 separate groups: patients who became pain free within the first 48 hours post-GKS; those who became pain free between 48 hours and 30 days post-GKS; and those who became pain free more than 30 days after GKS.

Results. The median age in the 497 patients was 68.3 years (range 28.1-93.2 years). The median follow-up period was 43.75 months (range 12-174.41 months). Four hundred fifty-four patients $(91.34 \%)$ were initially pain free within a median time of 10 days (range 1-459 days) after GKS. One hundred sixty-nine patients $(37.2 \%)$ became pain free within the first 48 hours $\left(\right.$ Group $\left.\mathrm{PF}_{\leq 48 \text { hours }}\right), 194$ patients $(42.8 \%)$ between posttreatment Day 3 and

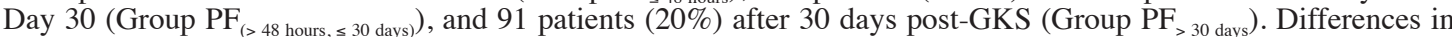
postoperative hypesthesia were found: in Group $\mathrm{PF}_{\leq 48 \text { hours }} 18$ patients $(13.7 \%)$ developed postoperative hypesthesia, compared with 30 patients $(19 \%)$ in Group $\mathrm{PF}_{(>48 \text { hours, }, 30 \text { days })}$ and 22 patients $(30.6 \%)$ in Group $\operatorname{PF}_{>30 \text { days }}(\mathrm{p}=0.014)$. One hundred fifty-seven patients $(34.4 \%)$ who initially became free from pain experienced a recurrence of pain with a median delay of 24 months (range $0.62-150.06$ months). There were no statistically significant differences between the patient groups with respect to pain recurrence: 66 patients $(39 \%)$ in Group $\mathrm{PF}_{\leq 48 \text { hours }}$ experienced pain recurrence, compared with 71 patients $(36.6 \%)$ in Group $\mathrm{PF}_{(>48 \text { hours }, \leq 30 \text { days })}$ and 27 patients $(29.7 \%)$ in Group $\mathrm{PF}_{>30 \text { days }}(\mathrm{p}=0.515)$.

Conclusions. A substantial number of patients (169 cases, $37.2 \%)$ became pain free within the first 48 hours. The rate of hypesthesia was higher in patients who became pain free more than 30 days after GKS, with a statistically significant difference between patient groups $(\mathrm{p}=0.014)$.

(http://thejns.org/doi/abs/10.3171/2012.8.GKS121015)

\section{KEY Words - freedom from pain - trigeminal neuralgia - pattern - Gamma Knife surgery • stereotactic radiosurgery • treatment response}

Abbreviations used in this paper: BNI = Barrow Neurological Institute; GKS = Gamma Knife surgery; Group PF = pain-free group; $\mathrm{MS}=$ multiple sclerosis; $\mathrm{TN}=$ trigeminal neuralgia.
ARS Leksell first introduced the concept of stereotactic radiosurgery in 1951 , when he treated a patient suffering from classic TN using a prototype-guiding device linked to a dental $\mathrm{x}$-ray machine. ${ }^{14}$ 
The use of GKS in the treatment of TN became more and more frequent starting in the 1990s, and an increasing number of articles confirming its safety and efficacy have appeared since $1996,,^{1-4,6,10,13,16-21,24}$ in what we called a "revolution" in functional neurosurgery in our recent editorial. ${ }^{22}$

The mechanisms of action that could explain the effectiveness of GKS for TN remain unclear, even though we now have persuasive evidence that demyelination of trigeminal sensory fibers plays an important role. ${ }^{15} \mathrm{Sev}$ eral animal studies have also been performed in attempts to clarify the pathophysiological aspects of postoperative GKS effects..$^{12,27}$

As we pointed out in our editorial, ${ }^{22}$ the number of articles about the role of GKS in the armamentarium for treating TN is continually growing. Thus far, few of them discuss the mechanism of action and neuromodulator effect of this radiosurgical technique because in many aspects the radiobiology remains unclear.

\section{Methods}

\section{Patient Population and Selection for Treatment}

Between July 1992 and November 2010, 737 patients presenting with intractable TN were treated with GKS and followed up prospectively at the Timone University Hospital in Marseille, France. We accepted for treatment patients fulfilling the criteria of the International Headache Society, ${ }^{7}$ which included long-standing pain refractory to pharmacological treatment with agents such as carbamazepine, phenytoin, baclofen, gabapentin, and so forth.

Four hundred ninety-seven patients with more than 1 year of follow-up comprised the study group that we finally analyzed. We deliberately excluded from our study patients whose TN was related to a megadolichobasilar artery or MS, as well as those who underwent a second GKS treatment. We focused only on cases of classic TN in which there was only 1 radiosurgical procedure.

\section{Radiosurgical Technique}

During this 18-year study, various models of the Gamma Knife (Elekta AB) were used: models B, C, 4C, and Perfexion. After a local anesthetic agent had been applied, the Leksell model G stereotactic frame (Elekta) was affixed to the patient head. All 497 patients (100\%) underwent stereotactic MR imaging and CT scanning so that we could identify the position of the trigeminal nerve. The MR imaging sequences that we used included T2weighted constructive interference in steady state without contrast and contrast-enhanced T1-weighted images. The CT routinely supplemented this imaging to correct any distortion errors on the MR images.

A single 4-mm isocenter was used for all 497 patients and was positioned in the cisternal portion of the trigeminal nerve, at a median distance of $7.8 \mathrm{~mm}$ (range 4.5-14 $\mathrm{mm}$ ) from the nerve's emergence from the brainstem.

Patients continued their medication unchanged for 1 month after GKS and then were able to diminish their drug doses depending on the treatment's efficacy. We normally saw these patients for a neurological examination, including an assessment of facial sensibility and motility and corneal reflex, at 3 months, 6 months, and 1 year post-GKS, and then yearly thereafter.

A team consisting of a neurosurgeon, radiation oncologist, and a medical physicist performed dose selection and planning.

\section{Follow-Up and Assessment of Outcome}

The director of Marseille-Mediterranean University and the ethical committee of Timone University Hospital approved our study. Follow-up information was obtained by direct clinical evaluation or telephone interview by the first author (C.T.), who was not involved in the selection of cases for treatment.

We evaluated the probability of onset of sensory disturbance and pain recurrence in patients who became pain free after GKS. We recorded and analyzed the preand post-GKS latency intervals, paying attention to date every event, the use of medication, the need for further surgical procedures, and so forth, as well as the time needed for every patient who became pain free to develop new or recurrent disorders, so that we could assess all available information accurately.

Pain was scored using the BNI pain scale, ${ }^{24}$ which uses the following grades: I, no trigeminal pain with no medication; II, occasional pain that does not require medication; IIIa, no pain with continued medication; IIIb, persistent pain controlled by medication; IV, some pain not adequately controlled by medication; and $\mathrm{V}$, severe pain with no relief.

For hypesthesia we used the BNI facial hypesthesia scale, ${ }^{24}$ which uses the following grades: I, no facial numbness; II, mild facial numbess but not bothersome; III, facial numbness that is somewhat bothersome; and IV, facial numbness that is very bothersome. For patients presenting with facial nerve sensory dysfunction, we inquired about their quality of life as it related to TN and whether this sensory problem bothered them. We also asked these patients whether they had mastication difficulties.

\section{Statistical Analysis}

Data were recorded using Microsoft Excel 2000. All statistical analyses were performed using R software (version 2.12.0, R Foundation for Statistical Computing). The survival $\mathrm{R}$ package was used for survival analysis.

We first conducted a descriptive analysis of recorded data for all 497 patients. We then compared the characteristics of all 3 groups, Analysis of variance was performed when conditions were verified; otherwise we performed the Kruskal-Wallis test. For qualitative variables, we performed the chi-square test when valid or the Fisher test otherwise.

To evaluate outcomes such as hypesthesia and pain recurrence, the time-to-event was estimated using the Kaplan-Meier method. A bivariate analysis was then performed to identify predictive factors among the collected variables. For qualitative variables, Kaplan-Meier curves were used to represent time-to-event graphically among 
the different groups and were compared using the univariate log-rank test. Proportionality of hazards was assessed graphically by using log cumulative hazard plots.

All tests were 2 -sided and $\mathrm{p}$ values $<0.05$ were judged to be significant.

\section{Evaluating and Deciding Patterns of Pain Free}

We tried to establish different patterns of pain-free responses. We used empirical tests to divide patients into different groups depending on the time that passed after GKS before they became pain free. We also made a chart showing the distribution of patients and clear cut-offs of freedom from pain (Fig. 1), with 2 major peaks, one at 2 days (48 hours) and the other at 30 days. Other small or medium peaks could be seen, but the number of patients achieving them was half or less compared with the other 2 peaks. That is why we finally chose 3 patient groups: patients who became pain free within the first 48 hours after GKS (Group $\mathrm{PF}_{\leq 48 \text { hours }}$ ); those who became pain free more than 48 hours after GKS but before or at 30 days after the procedure (Group $\left.\mathrm{PF}_{(>48 \text { hours, } \leq 30 \text { days })}\right)$; and those who became pain free more than 30 days after GKS $\left(\right.$ Group $\left.\mathrm{PF}_{>30 \text { days }}\right)$. We tested the patients' clinical parameters and tried to establish whether the rates of hypesthesia and pain recurrence were higher in one group or another. and if these results were statistically significant.

\section{Results}

\section{General Data}

The median age of the 497 patients was 68.3 years (range 28.1-93.2 years). The median age in Group $\mathrm{PF}_{\leq}$ 48 hours was 68.3 years (range 33.1-90.8 years), compared with 68.5 years (range 28.8-93.2 years) in Group $\mathrm{PF}_{(>}$ 48 hours, $\leq 30$ days) and 68.3 years (range $43.3-87.8$ years) in Group $\mathrm{PF}_{>30 \text { days }}(\mathrm{p}=0.991)$.

The median time between the first appearance of $\mathrm{TN}$ and treatment in Group $\mathrm{PF}_{\leq 48 \text { hours }}$ was 76.5 months (range 0.8-531 months), compared with 67.5 months (range 1-387.5 months) in Group $\mathrm{PF}_{(>48 \text { hours } \leq 30 \text { days })}$ and 71 months (range 5-529 months) in Group $\mathrm{PF}_{>30 \text { days }}(\mathrm{p}=$ $0.554)$.

The median follow-up period was 43.75 months (range 12-174.4 months).

Four hundred fifty-four patients (91.34\%) initially became pain free at a median time of 10 days (range 1-459 days) after GKS. Of these, 169 (37.2\%) became pain free within the first 48 hours (Group $\mathrm{PF}_{\leq 48 \text { hours }}$ ), compared with 194 (42.8\%) who became pain free between Day 3 and Day 30 (Group $\mathrm{PF}_{(>48 \text { hours, } \leq 30 \text { days) }}$ ) and 91 patients (20\%) who became pain free after 30 days (Group PF 30 days). Table 1 shows initial freedom from pain as well as the development of hypesthesia and pain recurrence within the 3 groups.

We studied the clinical parameters in all 3 subpopulations. The pre-GKS assessment showed no statistically significant differences (see Table 2 ) between the 3 groups regarding the side of the pain $(\mathrm{p}=0.73)$, presence of bilateral pain $(p=0.85)$, number of dermatomes involved in the pain $(\mathrm{p}=0.41)$, presence of atypical $(\mathrm{p}=0.805)$ or

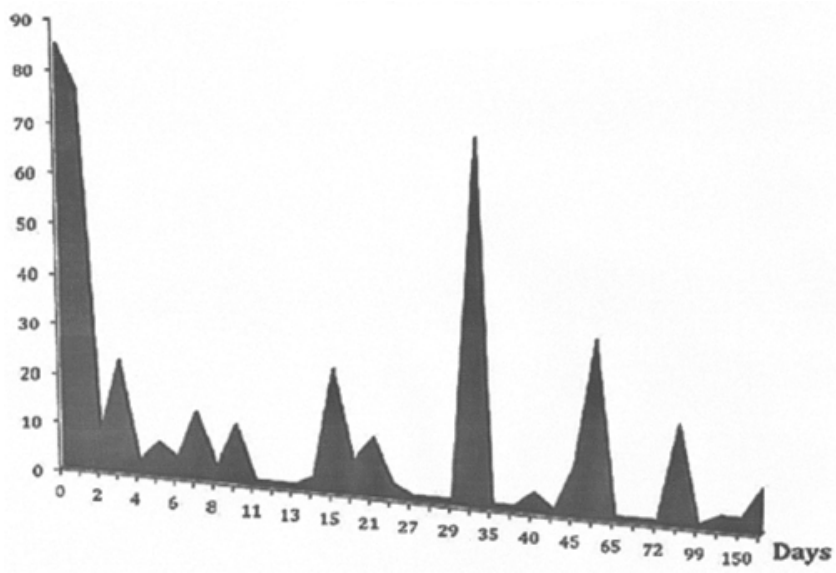

FIG. 1. Graph depicting the distribution of pain-free intervals after radiosurgery in a population of 497 patients with classic TN and only 1 GKS treatment. (Patients with megadolichobasilar artery- or MSrelated TN were not included in the study group.)

continuous $(\mathrm{p}=0.201)$ pain, neurovascular conflict evident on preoperative MR images ( $\mathrm{p}=0.743)$, or the sex of the patients $(\mathrm{p}=0.612)$.

The number and types of previous surgical interventions were also assessed. A summary is shown in Table 3 . Whether the patient had undergone previous surgical treatment $(p=0.576)$, the number of preoperative GKS interventions $(p=0.611)$, and most types of previous intervention-thermocoagulation on the same side $(\mathrm{p}=$ $0.565)$, balloon microcompression ( $p=0.982)$, microvascular decompression $(\mathrm{p}=0.999)$ and glycerol injection $(\mathrm{p}=1)$-were not statistically significant. Only previous contralateral thermocoagulation $(\mathrm{p}=0.04)$ was statistically significant for patterns of pain freedom.

Regarding preoperative hypesthesia, we found no statistically significant difference between the 3 painfree groups $(p=0.874)$, as seen in Table 4 . Only 1 person had preoperative anesthesia dolorosa; that patient was in Group $\mathrm{PF}_{\leq 48 \text { hours }}(\mathrm{p}=0.572)$.

TABLE 1: Initial freedom from pain in and development of hypesthesia and pain recurrence in the 3 patient groups ${ }^{*}$

\begin{tabular}{|c|c|c|c|c|}
\hline \multirow[b]{2}{*}{ Variable } & \multicolumn{3}{|c|}{$\begin{array}{c}\text { No. of Patients (\%) (total no. of } \\
\text { patients = 454) }\end{array}$} & \multirow[b]{2}{*}{ p Value } \\
\hline & Group 1 & Group 2 & Group 3 & \\
\hline initially pain free & $169(37.2)$ & $194(42.8)$ & $91(20)$ & \\
\hline hypesthesia & & & & 0.014 \\
\hline yes & 18 (13.7) & $30(19)$ & $22(30.6)$ & \\
\hline no & $113(86.3)$ & $128(81)$ & $50(69.4)$ & \\
\hline pain recurrence & & & & 0.515 \\
\hline yes & $59(34.9)$ & $71(36.6)$ & $27(29.7)$ & \\
\hline no & $110(65.1)$ & $123(63.4)$ & $64(70.3)$ & \\
\hline
\end{tabular}


TABLE 2: Preoperative assessment of the 3 patient groups regarding some clinical aspects and the neurovascular conflict seen on preoperative MR images

\begin{tabular}{|c|c|c|c|c|}
\hline \multirow[b]{2}{*}{ Variable } & \multicolumn{3}{|c|}{ No. of Patients (\%) } & \multirow[b]{2}{*}{ p Value } \\
\hline & Group 1 (169 patients) & Group 2 (194 patients) & Group 3 (91 patients) & \\
\hline side of pain & & & & 0.73 \\
\hline $\mathrm{rt}$ & $94(55.6)$ & $102(52.6)$ & $52(57.1)$ & \\
\hline It & $75(44.4)$ & $92(47.4)$ & $39(42.9)$ & \\
\hline bilat pain & & & & 0.85 \\
\hline yes & $7(4.1)$ & $6(3.1)$ & $4(4.4)$ & \\
\hline no & $162(95.9)$ & $188(96.9)$ & $87(95.6)$ & \\
\hline no. of territories of pain & & & & 0.41 \\
\hline 1 & $87(51.5)$ & $116(59.8)$ & $48(52.7)$ & \\
\hline 2 & $71(42)$ & $63(32.5)$ & $37(40.7)$ & \\
\hline 3 & $11(6.5)$ & $15(7.7)$ & $6(6.6)$ & \\
\hline atypical pain & & & & 0.805 \\
\hline yes & $36(21.3)$ & $37(19.1)$ & $20(22)$ & \\
\hline no & $133(78.7)$ & $157(80.9)$ & $71(78)$ & \\
\hline continuous pain & & & & 0.201 \\
\hline yes & $42(24.9)$ & $34(17.5)$ & $17(18.7)$ & \\
\hline no & $127(75.1)$ & $160(82.5)$ & $74(81.3)$ & \\
\hline $\begin{array}{l}\text { previous neurovascular } \\
\text { conflict seen on MRI }\end{array}$ & & & & 0.743 \\
\hline yes & $92(54.4)$ & $110(56.7)$ & $54(59.3)$ & \\
\hline no & $77(45.6)$ & $84(43.3)$ & $37(40.7)$ & \\
\hline sex of patient & & & & 0.612 \\
\hline male & $79(46.7)$ & $82(42.3)$ & $43(47.3)$ & \\
\hline female & $90(53.3)$ & $112(57.7)$ & $48(52.7)$ & \\
\hline
\end{tabular}

\section{Post-GKS Hypesthesia}

Among all 497 patients, the hypesthesia rate at 5 years was 20.4\%; at 7 years the rate reached $21.1 \%$ and remained stable until 14 years post-GKS, with a median delay of onset of 12 months (range 1-65 months).

Statistically significant differences $(p=0.014)$ between the 3 pain-free groups were identified for postGKS hypesthesia: postoperative sensory disturbances developed in 18 patients $(13.7 \%)$ in Group $\mathrm{PF}_{\leq 48 \text { hours }}$, compared with 30 patients (19\%) in Group $\mathrm{PF}_{(>48 \text { hours, } \leq 30 \text { days) }}$ and 22 patients (30.6\%) in Group $\mathrm{PF}_{>30 \text { days. }}$. Table 5 shows these findings. When hypesthesia was classified as mild or severe (discreet or important, respectively), the $\mathrm{p}$ value was 0.823 , and when it was assessed using the BNI scale, the $\mathrm{p}$ value was 0.598 .

Until 1 year after GKS, the risk of hypesthesia was similar in the 3 groups, but afterward there was a strong risk of hypesthesia in Group $\mathrm{PF}_{>30 \text { days }}$.

We conclude that the lowest hypesthesia rate was found in patients who became pain free earliest (Group $\mathrm{PF}_{\leq 48 \text { hours }}, 13.7 \%$ of patients) and the highest hypesthesia rate was found in patients who became pain free last (Group $\mathrm{PF}_{>30 \text { days }}, 30.6 \%$ of patients).

Figure 2 shows the probability of hypesthesia onset within the 3 subgroups.
Probability of Maintaining Pain Relief and Management of Pain Recurrence

One hundred fifty-seven patients $(34.4 \%)$ who became pain free after GKS experienced a recurrence of TN pain with a median delay of 24 months (range $0.62-$ 150.06 months).

There were no statistically significant differences in the pain recurrence rates between patient groups: 66 patients $(39 \%)$ in Group $\mathrm{PF}_{\leq 48 \text { hours }}, 71$ patients $(36.6 \%)$ in Group $\mathrm{PF}_{(>48 \text { hours, } \leq 30 \text { days })}$ and $27(29.7 \%)$ patients in Group $\mathrm{PF}_{>30 \text { days }}$ experienced at least 1 recurrence of pain $(\mathrm{p}=$ 0.515 ).

Whether patients underwent additional surgical intervention $(p=0.619)$; if performed, the number of additional surgical procedures $(\mathrm{p}=0.477)$; and the type of additional surgical intervention $(\mathrm{p}=0.849$ for thermocoagulation; $p$ $=0.873$ for balloon microcompression; $p=0.602$ for microvascular decompression; and $\mathrm{p}=1$ for cortical stimulation) were not found to be statistically significant. A summary of these findings is shown in Table 6 .

Figure 3 shows the probability of maintaining pain relief in the 3 subgroups.

\section{Evaluation of Outcome at the Last Follow-Up}

At the last follow-up, our results showed no statisti- 


\section{Radiosurgery for classic trigeminal neuralgia}

TABLE 3: Previous surgical intervention

\begin{tabular}{|c|c|c|c|c|}
\hline \multirow[b]{2}{*}{ Variable } & \multicolumn{3}{|c|}{ No. of Patients (\%) } & \multirow[b]{2}{*}{ p Value } \\
\hline & $\begin{array}{c}\text { Group } 1 \\
\text { (169 patients) }\end{array}$ & $\begin{array}{c}\text { Group } 2 \\
\text { (194 patients) }\end{array}$ & $\begin{array}{c}\text { Group } 3 \\
\text { (91 patients) }\end{array}$ & \\
\hline surgical treatment before GKS & & & & 0.576 \\
\hline yes & $61(36.1)$ & $60(30.9)$ & $31(34.1)$ & \\
\hline no & $108(63.9)$ & $134(69.1)$ & $60(65.9)$ & \\
\hline no. of surgeries before GKS & & & & 0.611 \\
\hline 0 & $108(63.9)$ & $134(69.1)$ & $60(65.9)$ & \\
\hline 1 & $38(22.5)$ & $36(18.6)$ & $16(17.6)$ & \\
\hline 2 & $15(8.9)$ & $12(6.2)$ & $11(12.1)$ & \\
\hline$\geq 3$ & $8(4.7)$ & $12(6.2)$ & $4(4.4)$ & \\
\hline previous thermocoagulation on same side & & & & 0.565 \\
\hline yes & $132(78.1)$ & $160(82.5)$ & $74(81.3)$ & \\
\hline no & $37(21.9)$ & $34(17.5)$ & $17(18.7)$ & \\
\hline previous contralateral thermocoagulation & & & & 0.045 \\
\hline yes & $4(2.4)$ & $194(100)$ & $0(0)$ & \\
\hline no & $165(97.6)$ & $194(100)$ & $91(100)$ & \\
\hline previous balloon microcompression & & & & 0.982 \\
\hline yes & $21(12.4)$ & $25(12.9)$ & $12(13.2)$ & \\
\hline no & $148(87.6)$ & $169(87.1)$ & $79(86.8)$ & \\
\hline previous microvascular decompression & & & & 0.999 \\
\hline yes & $13(7.7)$ & $15(7.7)$ & $7(7.7)$ & \\
\hline no & $156(92.3)$ & $179(92.3)$ & $84(92.3)$ & \\
\hline previous glycerol injection & & & & 1 \\
\hline yes & $1(0.6)$ & $2(1)$ & $0(0)$ & \\
\hline no & $168(99.4)$ & $192(99)$ & $91(100)$ & \\
\hline previous contralateral GKS & & & & 0.08 \\
\hline yes & $0(0)$ & $5(2.6)$ & $1(1.1)$ & \\
\hline no & $169(100)$ & $189(97.4)$ & $90(98.9)$ & \\
\hline
\end{tabular}

cally significant differences between the 3 subgroups ( $p$ $=0.874$ for the BNI classification). Table 7 shows these results.

\section{Discussion}

Even if the role of GKS in the armamentarium for treating $\mathrm{TN}$ is now well established, the radiobiological mechanisms of action associated with the procedure remain poorly understood.

When we discuss clinical and histopathological chains of events we cannot separate the causes of TN, which can differ greatly from one case to another: compression by an overlying artery or vein (thought to account for $80 \%-90 \%$ of cases $^{9}$ ) with focal demyelination, close apposition of demyelinated axons, few residual oligodendrocytes, and no inflammatory cells; ${ }^{8}$ primary demyelinating disorders (MS) with demyelination extending along the proximal part of the trigeminal nerve root and, in some cases, to the junction with the peripheral nerve system, juxtaposed axons, and the presence of variable thinly myelinated fibers; masses in the posterior fossa, small infarcts or angiomas in the pons or medulla oblongata, prosthetic materials inserted during microvascular decompression; ${ }^{5}$ bone compression of the nerve; ${ }^{23,25}$ and idiopathic cases or, less frequently, familial TN..$^{11}$ In the majority of cases, the cause of TN seems to be demyelination, especially present at the level of the trigeminal root entry zone..$^{15}$

Few studies have been conducted to understand the mechanism of action that occurs when GKS is used as a tool for treatment.

TABLE 4: Preoperative hypesthesia in the 3 patient groups

\begin{tabular}{lcccc}
\hline & \multicolumn{3}{c}{ No. of Patients (\%) } & \\
\cline { 2 - 4 } & Group 1 & Group 2 & Group 3 & \\
Preop Hypesthesia & patients) & patients) & patients) & Value \\
\hline no hypesthesia & $131(77.5)$ & $158(81.4)$ & $72(79.1)$ & \\
slight hypesthesia & $34(20.1)$ & $33(17)$ & $18(19.8)$ & 0.874 \\
severe hypesthesia & $4(2.4)$ & $3(1.5)$ & $1(1.1)$ & \\
\hline
\end{tabular}




\begin{tabular}{|c|c|c|c|c|}
\hline \multirow[b]{2}{*}{ Variable } & \multicolumn{3}{|c|}{ No. of Patients (\%) } & \multirow[b]{2}{*}{$\mathrm{p}$ Value } \\
\hline & $\begin{array}{c}\text { Group } 1 \\
\text { (169 patients) }\end{array}$ & $\begin{array}{c}\text { Group } 2 \\
\text { (194 patients) }\end{array}$ & $\begin{array}{c}\text { Group } 3 \\
\text { (91 patients) }\end{array}$ & \\
\hline hypesthesia after GKS & & & & 0.014 \\
\hline yes & $18(13.7)$ & $30(19)$ & $22(30.5)$ & \\
\hline no & $113(86.3)$ & $128(81)$ & $50(69)$ & \\
\hline type of hypesthesia & & & & 0.823 \\
\hline discrete & $13(72.2)$ & $21(70)$ & $14(63.6)$ & \\
\hline important & $5(27.8)$ & $9(30)$ & $8(36.4)$ & \\
\hline BNI type of hypesthesia & & & & 0.598 \\
\hline mild facial numbness & $15(83.3)$ & $27(90)$ & $18(81.8)$ & \\
\hline facial numbness, somewhat bothersome & $2(11.1)$ & $3(10)$ & $3(13.6)$ & \\
\hline facial numbness, very bothersome & $1(5.6)$ & $0(0)$ & $1(4.6)$ & \\
\hline
\end{tabular}

Kondziolka et al. ${ }^{12}$ irradiated 2 male baboons (Papio cynocephalus anubis) using doses of 80 and 100 Gy. Light and electron microscopic examinations were performed to analyze specimens of the trigeminal nerve 6 months after the procedure. The authors discovered acute degenerating axons with some identifiable myelinated axons, small foci of necrosis (including Schwann cell nuclei necrosis), and normal trigeminal ganglion when they used 80 Gy. At 100-Gy doses they found axon degeneration with myelin vacuolation and expansion of the endoneurial intracellular matrix, which was consistent with edema. In one specimen, almost the entire width of the nerve was necrotic. Axon degeneration was noted outside the necrotic zone, but the histological features normalized toward the ganglion. The authors concluded that the histological effects were dose related and consisted of

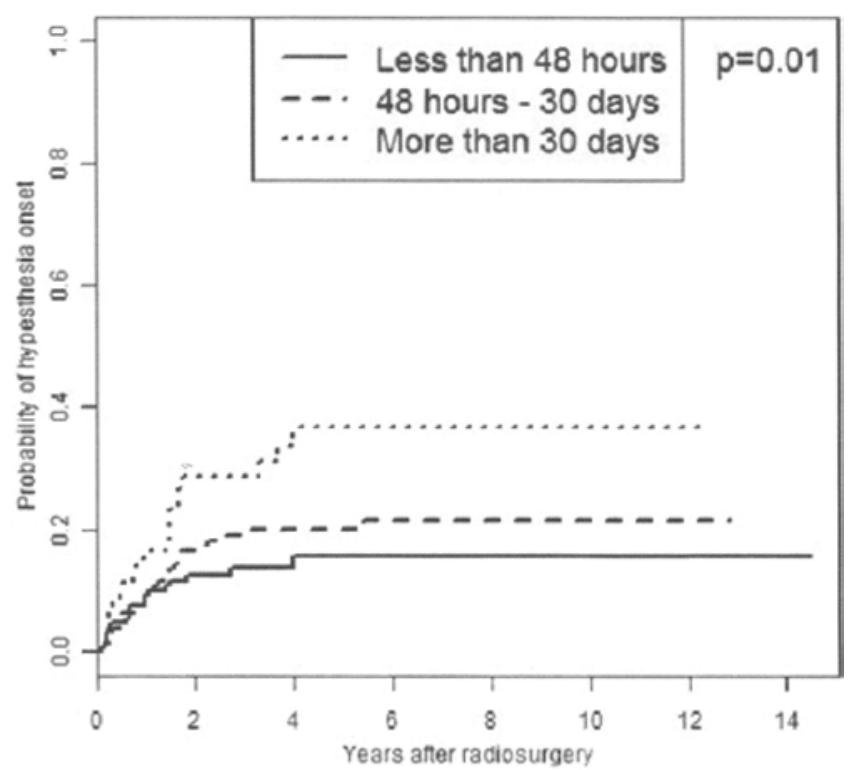

FIG. 2. Post-GKS hypesthesia in the 3 pain-free patient subgroups: Group $\mathrm{PF}_{\leq 48 \text { hours }}$, Group $\mathrm{PF}_{(>48 \text { hours, } \leq 30 \text { days })}$, and Group $\mathrm{PF}_{>30 \text { days }}$ * primary axon injuries. They also observed no evidence of inflammation 6 months after GKS, and the extent of nerve edema was mild. Kondziolka et al. presumed that acute inflammation likely occurs after nerve irradiation (perhaps within the first few days) and may have effects on pathophysiological nerve processes, relieving pain quickly.

Szeifert et al. ${ }^{26}$ studied the histopathological findings in a patient who suffered from $\mathrm{TN}$ and was treated 2 times by GKS (in the first procedure, the maximum dose was $90 \mathrm{~Gy}$; in the second procedure, performed 10 months later, the maximum dose was $70 \mathrm{~Gy}$ ). The patient died of a hemorrhagic stroke 26 days following the second intervention, and an autopsy was performed. Histopathological studies demonstrated changes in the trigeminal nerve that differed according to the sites of each treatment dose. Chronic radiation-induced changes were identified 11 months after the first treatment, at the site treated with $90 \mathrm{~Gy}$ : there was a well-circumscribed, hypocellular fibrotic lesion with hyaline-degenerated collagen bundles and scattered fibrocytes. Acute radiation-induced changes, indicative of the early consequences of radiosurgery, were identified 26 days after the second treatment, at the site treated with 70 Gy: there was a sharply demarcated necrotic center containing fibrinoid material and tissue debris, which was encircled by surviving nerve bundles.

\section{Conclusions}

Our study was rather empirical (but also based on a statistical chart of distribution) in classifying the distribution of pain-free patients into the 3 subtypes. Our data indicate that pathophysiological mechanisms similar to those described in the other cited studies could be involved, but also some new ones-unknown for the moment-that could help explain the different patterns of freedom-from-pain responses after GKS. A substantial number of patients, 169 (37.2\%), became pain free within the first 48 hours (Group $\mathrm{PF}_{\leq 48 \text { hours }}$ ) after GKS; this is quite a large population. These patients had the lowest rate of hypesthesia in our series (13.7\%), particu- 


\section{Radiosurgery for classic trigeminal neuralgia}

TABLE 6: Management of pain recurrence with number and type of further surgical interventions

\begin{tabular}{|c|c|c|c|c|}
\hline \multirow[b]{2}{*}{ Variable } & \multicolumn{3}{|c|}{ No. of Patients (\%) } & \multirow[b]{2}{*}{ p Value } \\
\hline & $\begin{array}{c}\text { Group } 1 \\
\text { (169 patients) }\end{array}$ & $\begin{array}{c}\text { Group } 2 \\
\text { (194 patients) }\end{array}$ & $\begin{array}{c}\text { Group } 3 \\
\text { (91 patients) }\end{array}$ & \\
\hline surgical treatment after GKS & & & & 0.619 \\
\hline yes & $33(19.5)$ & $39(20.1)$ & $14(15.4)$ & \\
\hline no & $136(80.5)$ & $155(79.9)$ & $77(84.6)$ & \\
\hline no. of surgeries after GKS & & & & 0.477 \\
\hline 1 & $26(78.8)$ & $28(71.8)$ & $8(57.1)$ & \\
\hline 2 & $6(18.2)$ & $9(23.1)$ & $4(28.6)$ & \\
\hline$\geq 3$ & $1(3)$ & $2(5.1)$ & $2(14.3)$ & \\
\hline further thermocoagulation & & & & 0.849 \\
\hline yes & $10(30.3)$ & $10(25.6)$ & $3(21.4)$ & \\
\hline no & $23(69.7)$ & $29(74.4)$ & $11(78.6)$ & \\
\hline further balloon microcompression & & & & 0.873 \\
\hline yes & $19(57.6)$ & $22(56.4)$ & $9(64.3)$ & \\
\hline no & $14(42.4)$ & $17(43.6)$ & $5(35.7)$ & \\
\hline further microvascular decompression & & & & 0.602 \\
\hline yes & $4(12.1)$ & $8(20.5)$ & $3(21.4)$ & \\
\hline no & $29(87.9)$ & $31(79.5)$ & $11(78.6)$ & \\
\hline further cortical stimulation & & & & 1 \\
\hline yes & $0(0)$ & $1(2.6)$ & $0(0)$ & \\
\hline no & $33(100)$ & $38(97.4)$ & $14(100)$ & \\
\hline
\end{tabular}

larly compared with patients in the Group $\mathrm{PF}_{>30 \text { days }}$, in which hypesthesia developed in 22 patients (30.6\%) (data statistically significant, $\mathrm{p}=0.014$ ). The pain recurrence rate was $39 \%$ in Group $\mathrm{PF}_{\leq 48 \text { hours }}$, compared with $26.6 \%$ in Group $\mathrm{PF}_{(>48 \text { hours, } \leq 30 \text { days })}$ and $29.7 \%$ in Group $\mathrm{PF}_{>30 \text { days }}$, but these data were not statistically significant $(p=0.515)$.

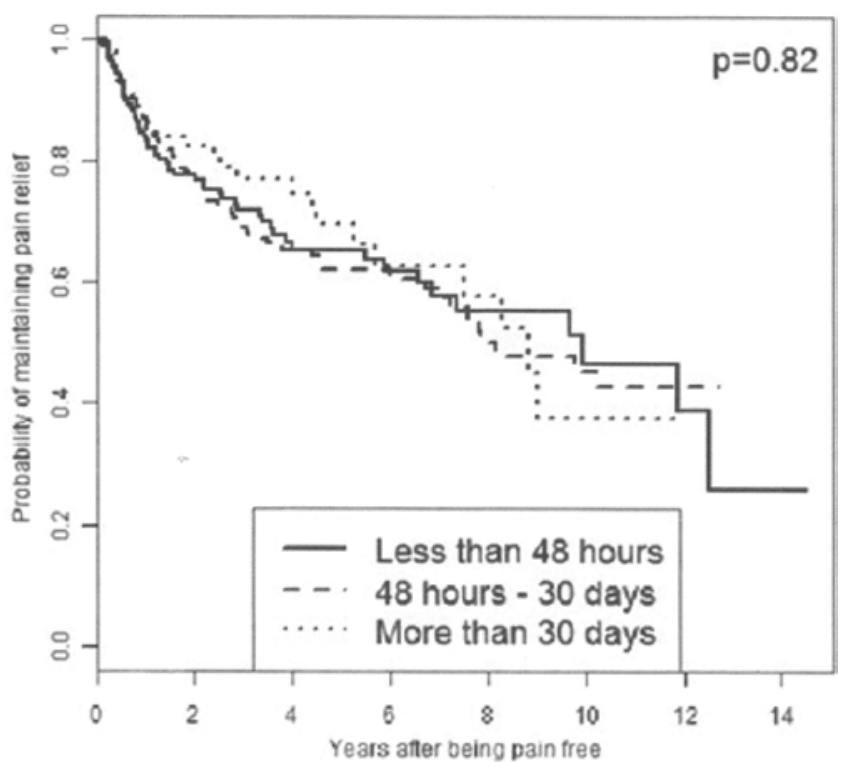

FIG. 3. Probability of maintaining pain relief in the 3 pain-free patient subgroups: Group $\mathrm{PF}_{\leq 48 \text { hours }}$, Group $\mathrm{PF}_{(>48 \text { hours }, \leq 30 \text { days })}$, and Group $\mathrm{PF}_{>30 \text { days }}$.
Given that targeting a small volume of normal tissue with a high radiation dose probably does not produce a destructive effect, the neuromodulatory mechanisms of GKS still need to be further analyzed and understood.

\section{Disclosure}

Professor Régis declares receiving support for non-study related clinical or research effort from Elekta AB. No other potential conflicts have been reported.

Author contributions to the study and manuscript preparation include the following. Conception and design: Tuleasca, Carron, Levivier, Régis. Acquisition of data: Tuleasca. Analysis and interpretation of data: Tuleasca, Resseguier, Gaudart. Drafting the article: Tuleasca. Critically revising the article: all authors. Reviewed submitted version of manuscript: all authors. Approved the final version of the manuscript on behalf of all authors: Tuleasca. Statistical analysis: Resseguier, Gaudart. Administrative/technical/material

\section{TABLE 7: Outcome at the last follow-up based on BNI} classification

\begin{tabular}{ccccc}
\hline & \multicolumn{3}{c}{ No. of Patients (\%) } & \\
\cline { 2 - 4 } & Group 1 & Group 2 & Group 3 & \\
Variable & $(169$ & $(194$ & $(91$ & $p$ \\
patients) & patients) & patients) & Value \\
\hline BNI classification & & & & 0.874 \\
good outcome & $165(97.6)$ & $188(96.9)$ & $88(96.7)$ & \\
poor outcome & $4(2.4)$ & $6(3.1)$ & $3(3.3)$ & \\
\hline
\end{tabular}


support: Tuleasca, Donnet, Roussel, Levivier, Régis. Study supervision: Donnet, Roussel, Gaudart, Levivier, Régis.

\section{References}

1. Brisman R: Gamma knife radiosurgery for primary management for trigeminal neuralgia. J Neurosurg 93 (Suppl 3): 159-161, 2000

2. Brisman R, Mooij R: Gamma knife radiosurgery for trigeminal neuralgia: dose-volume histograms of the brainstem and trigeminal nerve. J Neurosurg 93 (Suppl 3):155-158, 2000

3. Flickinger JC, Pollock BE, Kondziolka D, Phuong LK, Foote RL, Stafford SL, et al: Does increased nerve length within the treatment volume improve trigeminal neuralgia radiosurgery? A prospective double-blind, randomized study. Int J Radiat Oncol Biol Phys 51:449-454, 2001

4. Fountas KN, Lee GP, Smith JR: Outcome of patients undergoing gamma knife stereotactic radiosurgery for medically refractory idiopathic trigeminal neuralgia: Medical College of Georgia's experience. Stereotact Funct Neurosurg 84:8896, 2006

5. Fujimaki T, Hoya K, Sasaki T, Kirino T: Recurrent trigeminal neuralgia caused by an inserted prosthesis: report of two cases. Acta Neurochir (Wien) 138:1307-1310, 1996

6. Han JH, Kim DG, Chung HT, Paek SH, Kim YH, Kim CY, et al: Long-term outcome of gamma knife radiosurgery for treatment of typical trigeminal neuralgia. Int J Radiat Oncol Biol Phys 75:822-827, 2009

7. Headache Classification Subcommitee of the International Headache Society: The International Classification of Headache Disorders: 2nd edition. Cephalalgia 24 Suppl 1:9-160, 2004

8. Hilton DA, Love S, Gradidge T, Coakham HB: Pathological findings associated with trigeminal neuralgia caused by vascular compression. Neurosurgery 35:299-303, 1994

9. Jannetta PJ: Neurovascular compression in cranial nerve and systemic disease. Ann Surg 192:518-525, 1980

10. Knafo H, Kenny B, Mathieu D: Trigeminal neuralgia: outcomes after gamma knife radiosurgery. Can J Neurol Sci 36: 78-82, 2009

11. Knuckey NW, Gubbay SS: Familial trigeminal and glossopharyngeal neuralgia. Clin Exp Neurol 16:315-319, 1979

12. Kondziolka D, Lacomis D, Niranjan A, Mori Y, Maesawa S, Fellows W, et al: Histological effects of trigeminal nerve radiosurgery in a primate model: implications for trigeminal neuralgia radiosurgery. Neurosurgery 46:971-977, 2000

13. Kondziolka D, Zorro O, Lobato-Polo J, Kano H, Flannery TJ, Flickinger JC, et al: Gamma Knife stereotactic radiosurgery for idiopathic trigeminal neuralgia. Clinical article. J Neurosurg 112:758-765, 2010

14. Leksell L: Sterotaxic radiosurgery in trigeminal neuralgia. Acta Chir Scand 137:311-314, 1971

15. Love S, Coakham HB: Trigeminal neuralgia: pathology and pathogenesis. Brain 124:2347-2360, 2001
16. Lunsford LD, Young RF: Radiosurgery for trigeminal neuralgia. Surg Neurol 54:285-287, 2000

17. Massager N, Lorenzoni J, Devriendt D, Desmedt F, Brotchi J, Levivier M: Gamma knife surgery for idiopathic trigeminal neuralgia performed using a far-anterior cisternal target and a high dose of radiation. J Neurosurg 100:597-605, 2004

18. Massager N, Lorenzoni J, Devriendt D, Levivier M: Radiosurgery for trigeminal neuralgia. Prog Neurol Surg 20:235-243, 2007

19. Pollock BE, Phuong LK, Gorman DA, Foote RL, Stafford SL: Stereotactic radiosurgery for idiopathic trigeminal neuralgia. J Neurosurg 97:347-353, 2002

20. Régis J, Arkha Y, Yomo S, Murata N, Roussel P, Donnet A, et al: [Radiosurgery in trigeminal neuralgia: long-term results and influence of operative nuances.] Neurochirurgie 55:213222, 2009 (Fr)

21. Régis J, Metellus P, Hayashi M, Roussel P, Donnet A, BilleTurc F: Prospective controlled trial of gamma knife surgery for essential trigeminal neuralgia. J Neurosurg 104:913-924, 2006

22. Régis J, Tuleasca C: Fifteen years of Gamma Knife surgery for trigeminal neuralgia in the Journal of Neurosurgery: history of a revolution in functional neurosurgery. Editorial. J Neurosurg 115 Suppl:2-7, 2011

23. Reilly MM, Valentine AR, Ginsberg L: Trigeminal neuralgia associated with osteogenesis imperfecta. J Neurol Neurosurg Psychiatry 58:665, 1995

24. Rogers CL, Shetter AG, Fiedler JA, Smith KA, Han PP, Speiser BL: Gamma knife radiosurgery for trigeminal neuralgia: the initial experience of The Barrow Neurological Institute. Int J Radiat Oncol Biol Phys 47:1013-1019, 2000

25. Ruelle A, Datti R, Andrioli G: Cerebellopontine angle osteoma causing trigeminal neuralgia: case report. Neurosurgery 35:1135-1137, 1994

26. Szeifert GT, Salmon I, Lorenzoni J, Massager N, Levivier M: Pathological findings following trigeminal neuralgia radiosurgery. Prog Neurol Surg 20:244-248, 2007

27. Zhao ZF, Yang LZ, Jiang CL, Zheng YR, Zhang JW: Gamma Knife irradiation-induced histopathological changes in the trigeminal nerves of rhesus monkeys. Laboratory investigation. J Neurosurg 113:39-44, 2010

Manuscript submitted May 19, 2012.

Accepted August 1, 2012.

Portions of this study were presented in abstract form at the 16th International Meeting of the Leksell Gamma Knife Society, Sydney, Australia, March 2012.

Please include this information when citing this paper: DOI: 10.3171/2012.8.GKS121015.

Address correspondence to: Constantin Tuleasca, M.D., Centre Hospitalier Universitaire Vaudois, Neurosurgery Service and Gamma Knife Center, Rue de Bugnon 44-46, BH-08, CH-1011 Lausanne, Switzerland. email: constantin.tuleasca@gmail.com. 